\title{
The Application of AI as Reinforcement in the Intervention for Children With Autism Spectrum Disorders (ASD)
}

\author{
Jing SHI ${ }^{1}$ \\ ${ }^{1}$ Guangdong University of Foreign Studies, Guangzhou, P.R.China \\ Correspondence: Jing SHI, Guangdong University of Foreign Studies, Guangzhou 510420, Guangdong, \\ P.R.China. E-mail: sj@oamail.gdufs.edu.cn
}

This essay is supported by MOE (Ministry of Education in China) Project of Humanities and Social Sciences for the Youth "Research on Pragmatic Intervention for HFA Children"(Project code: 19YJCZH136); Guangzhou 13 ${ }^{\text {th }}$ Five-Year Planning Project " Pragmatic Intervention for HFA Children(Project code: 2019GZGJ61) " Reform and Innovation Project of Guangdong University of Foreign Studies "The Analysis and Intervention of Pragmatic Deficits of HFA Children "(Project code: 18TS07).

\author{
Received: May 15, 2018 Accepted: June 9, 2018 Online Published: June 19, 2018 \\ doi:10.5539/jedp.v9n2p17 \\ URL: http://doi.org/10.5539/jedp.v9n2p17
}

\begin{abstract}
Autism Spectrum Disorders (ASD) is a neuro-developmental disorder. There is a tremendous variability in individuals with ASD; however, it is mainly characterized by social behavioral deficits. Across the globe, the prevalence of ASD is fairly consistent and the most current estimates are 1 in 59. There is no biological cure for people with ASD and intervention is widely accepted as the only solution for them to improve the quality of their lives. Among all the treatments, Applied Behavior Analysis (ABA) has more quantity of evidence than other methods and it has more studies with the strongest levels of evidence. Using reinforcement is a vital and indispensable part of ABA. Many researches reveal that children with ASD are more likely to become interested in robots or other forms of Artificial Intelligence (AI) and in fact AI is used in the intervention for children with ASD. The application of AI has been proven to be feasible and effective in the interventions. This essay aims at analyzing the effects of the application of $\mathrm{AI}$ as reinforcement in $\mathrm{ABA}$ and providing suggestions for application of $\mathrm{AI}$ in other aspects of $\mathrm{ABA}$ intervention. Hopefully this essay will be suggestive for the future application of $\mathrm{AI}$ in terms of assisting the intervention for children with ASD in order to reduce the workload and cost.
\end{abstract}

Keywords: Autism Spectrum Disorders, children, intervention

\section{Introduction}

Autism Spectrum Disorders (ASD) is a neuro-developmental disorder. There is a tremendous variability in individuals with ASD. There are social behavioral deficits that comprise the symptom profile of people with ASD. The diagnostic criteria for ASD include three social impairments in the following areas: 1) Social-emotional reciprocity which includes: difficulties with conversation, lack of sharing interests, and failure to initiate and respond to social interactions; 2) nonverbal communication which includes: eye contact, facial expressions, and nonverbal communication in general; 3) relationships which includes lack of interest in peers, difficulties in imaginary play, failure to make friends, and adjust one's behavior to fit the social context (American Psychiatric Association 2013; World Health Organization 2018). ASD is characterized by behavioral deficits. In order to receive the diagnosis, individuals need to have two of the four following symptoms: 1) excessive repetitive behavior in motor movements, object use and speech; 2) insistence on sameness, inflexible routines, or ritualized behavior; 3) abnormally intense interests, or interests with an unusual focus; 4) concerns a hyper- or hypo sensitivity to sensory stimuli (American Psychiatric Association 2013; World Health Organization 2018). Although the diagnostic symptoms of ASD are social and behavioral in nature, ASD is also characterized by language, intellectual and motor deficits. Not necessarily everybody with ASD has these deficits: people with ASD more likely to have deficits in those areas. ASD has a genetic basis and there is also environmental influence. ASD actually begins at birth or shortly thereafter, symptoms might not be noticeable until the child become 2 years old. Across the globe, the prevalence of ASD is fairly consistent. It was believed around 1 in 150 individuals had ASD 15 years ago. The most current estimates are 1 in 59. It is not actually because more people have ASD but because 
pediatricians become more aware of it and there is a change in the diagnostic criteria themselves which allow more people receive the diagnosis. The disorder is more common in boys than it is in girls, and about 4 times as many boys who receive the diagnosis than girls.

Since there is no biological cure for ASD, early intervention and education for children with ASD is reckoned to be the only feasible way to relieve the symptoms and improve the quality of their lives. There are hundreds of treatments which are claimed to be effective and helpful towards children with ASD; however, Applied Behavior Analysis (ABA) is the only treatment that has strong scientific support for its effectiveness. Since the 1980s, regular researches have shown ABA is evidence-based treatment. In the U.S., both the National Research Council and American Academy of Pediatrics identify ABA as the most effective treatment for individuals diagnosed with ASD. Using reinforcement is an indispensable part of shaping and reshaping children's behavior when implementing ABA intervention. Many researches reveal that children with ASD are more likely to interact with $\mathrm{AI}$ rather than caregivers and peers, because $\mathrm{AI}$ seems less disturbing and more simple than human beings. $\mathrm{AI}$ is an ideal

\section{Literature Review: AI-Assisted Intervention for Children With ASD}

Evidence-based interventions are generally time-consuming and very expensive. Artificial Intelligence is reckoned to be an effective tool to cut off the high cost of labor and time. Several researches focus on the functions of AI on the improvement of social abilities of children with ASD. Huijnen et al. (2016) have evaluated 14 identified robots in peer reviewed journals applied in studies with children with ASD, basically assessing these robots' operating mode and their functions on the social abilities of children with ASD. The aim of the research is to increase knowledge on therapy and educational objectives that professionals work on with children with ASD. It implies that AI can potentially be applied to a large scope of objectives for children with ASD, which functions as a base to guide development of robot interventions. The research tries to map AI's route to the intervention for children with ASD in a general way. The pilot study carried out by Warren et al. (2013) focuses on one specific area of AI's function on children with ASD: whether robotic interaction can actually improve joint attention skills of children with ASD. Joint attention skills are thought to be one of the most important aspects of social skills. Results reveal that children improved in their ability to orient to prompts administered by the robotic system and continued to display strong attention to the humanoid robot. The research highlights the potential benefits as well as potent limitations of application of AI in the improvement of joint attention skills of ASD children. Simut (2015)'s focus is on robots' functions on other aspects of social skills. The findings of the results show that children participating in the research had more eye-contact with the social robot compared to that with the human. The conditions did not differ regarding the interaction elicited with the human accompanying the child. These researches have proved the effectiveness of AI's application in the interventions for children with ASD in a general way. In 2018, Huijnen et al. (2018) conducted a research, studying roles, strengths and challenges of robot-mediated interventions by using robot KASPAR for children with ASD. This research has given a big picture of the function of the most cutting-edge humanoid on children with ASD.

Still, very few research focuses on AI's function on one of the most essential features of ABA: reinforcement. This longitudinal research is to conduct a pilot study, aiming at analyzing AI's function as a reinforcer in ABA intervention and hoping to provide constructive suggestions for the application of AI as an effective reinforcer in ABA interventions.

\section{Theoretical Framework: AI-An Ideal Reinforcement}

There are several prevalent treatments for ASD and the beliefs underlined those treatments. Applied Behavior Analysis (ABA) is the only treatment that has strong scientific support for its effectiveness. Since the 1980s, regular research have shown ABA is evidence-based treatment. In the U.S., both the National Research Council and American Academy of Pediatrics identify ABA as the most effective treatment for individuals diagnosed with ASD. There are actually several different approaches that fall under the ABA umbrella (National Autism Center, 2015). Each approach has their own views regarding training, teaching style and priorities.

The first approach illustrated is Verbal Behavior (VB) therapy. VB is based on ABA principles and theories of B.F. Skinner (1957). The therapy teaches vocal or non-vocal languages by linking words to their functions (Sundberg 2008, 2014). It believes that improved language skills will lead to the reduction of disruptive behavior. Interventionists would believe anybody can learn language. They provide frequent and immediate prompts while following the child's need during the therapy sessions. There is research demonstrating the effectiveness of VB in teaching language acquisition, but it lacks evidence for its improving daily living skills and overall outcome (Stolte et al., 2016; Montallana et al., 2019). 
Pivotal Response Treatment (PRT) is another therapy that relies on the principles of ABA. Interventionists focus on specific areas of development and believe that improvements in those areas will lead to improvement in other areas. Pivotal areas include: motivation, response to multiple cues, self-management and initiation of social interaction. The approach is child-directed, and incorporates the elements of natural language training. There is evidence to support this treatment's effectiveness (Ventola et al., 2016; Duifhui et al., 2017; Bradshaw et al., 2017; Versschuur et al., 2017; Brock et al., 2018; Vernon et al., 2019).

Treatment and Education of Autistic and Related Communication Handicapped Children (TEACCH) was founded in the 1970s and it is based on the assumption that the symptoms of ASD are lifelong impairments intractable. TEACCH is a behavioral treatment but is not exactly ABA. Core aspects of the intervention involves accommodations, such as eliminating distractions, and providing ample visual cues. A 2013 review of TEACCH found that: those received the intervention made meaningful social and behavioral gains; however, they did not make meaningful gains in perceptual, motor, verbal and cognitive skills. Also, they made very limited gains in communication and daily living skills (Park et al., 2018; Alateeqi et al., 2019; Fuller et al., 2019).

In addition to $\mathrm{ABA}$ approaches, there are other treatments which are not based on evidence. The relationship-based treatments hypothesize that the primary social deficit in ASD comes from a disturbed relationship between the child and the primary caregiver. Floortime is a developmental intervention that emphasizes relationship and engagement in order for a child to develop a sense of self. It involves meeting a child's developmental level and challenging them to move up the hierarchy (Mercer, 2017; Movahedazarhouligh, 2018). Relationship Development Intervention (RDI) is designed to improve communication and social skills by exposing authentic emotional relationships in a gradual and systematic way (Hobson et al., 2016; Loucas et al., 2016).

There are also education-based alternative treatments. Social Thinking is a discussion-based intervention for adolescents with advanced cognitive and language skills. Individuals discuss why a skill is important and how thinking about the social world can help them adapt. Social Story is a psycho-educational intervention which provides detailed descriptions of social situations and responses to help the student navigate social experiences successfully (Crooke et al., 2016; Muller et al., 2016; Juliet, 2018; Bottema-Beutel et al., 2018; Grenier et al., 2019).

Reinforcement is a vital component of any teaching programme. For children with ASD, they need more reinforcement than the natural environment can provide. They may not know how to play with toys or they find it difficult to do so. Common social contingency may not be motivating to them. Typical play may not be enjoyable to them as they may be reinforced by sensory interests or negative attention. As a result, caregivers or teachers often need to develop reinforcer. It is necessary to decide what item or activity may be able to be turned into a true reinforcer. We have to 1) consider using appropriate existing preferences and take advantage of the child's personal preferences, 2) vary current preferences and include even the stereotyped behavior into the activity, such as, if the child like running all around we can play chase, 3 ) try several toys that the child seldom access to and see which one he likes. Although we do not have complete control of what a child would find reinforcing, we can certainly influence their preferences. We can 1) limit access to powerful reinforcers, 2) pair new reinforcers with current ones, 3) sell the reinforcer. On the surface, potential reinforcers might not all seem to be interesting to children with ASD. It is up to the teachers to make them fun. There are several ways to make the reinforcer more enticing to the child. Reinforcers can be shown in a variety of ways with creative presentations; elements of surprise and suspense can make children with ASD more excited to play the reinforcer; enthusiastic tone and positive facial expression, go along with sound effects and comments can also make the reinforcer seem more appealing; physical contacts like tickles can make some children with ASD will link a new reinforcer with fun time. A humanoid robot is assumed to be an effective reinforcer because: 1) the robot which is originally designed to accompany children is age appropriate; 2) it is practical and easy to deliver; 3 ) the humanoid robot involved in this program is portable and user-friendly which can be used repeatedly and regularly; 4) the humanoid robot is not solitary and can be easily during other activities (Beaver et al., 2017; Anderson et al., 2017; Johnson et al., 2017; Jessel et al., 2017; Fritz et al., 2017; MacNaul et al., 2018; Goldman et al., 2019; Matsuda et al., 2019; Vandbakk et al., 2019). This research attempts to test the effectiveness of the humanoid Wukong as being the reinforcer applied in an intensive ABA intervention program.

\section{Application of AI as Reinforcement in ABA Intervention: A Single-Case Study}

The AI involved in this research is Wukong, a humanoid robot for education and entertainment, designed by Ubtech. The product parameters of Wukong are listed in the following chart. 
Table 1. Product Parameters of Wukong

\begin{tabular}{lllll}
\hline & Dimension & $245 * 149 * 112 \mathrm{~mm}$ & Internal memory & RAM 2GB/ ROM 16 GB \\
\hline Weight & $700 \mathrm{~g}$ & Control method & Dual-mode bluetooth \\
\hline Color & white & Battery & $\begin{array}{l}3.85 \mathrm{v} \\
\text { lithiumbattery }\end{array}$ \\
\hline Materials & $\begin{array}{l}\text { aluminum alloy structure, } \\
\text { ABS housing }\end{array}$ & $\begin{array}{l}\text { System } \\
\text { compatibility }\end{array}$ & iOS/Android \\
\hline $\begin{array}{l}\text { DOF } \\
\text { (Degree }\end{array}$ & $\begin{array}{l}14 \text { degrees of freedom } \\
\text { (head 3; hands 2*2; waist 1; } \\
\text { Freedom })\end{array}$ & $\begin{array}{l}\text { Software } \\
\text { programming }\end{array}$ & $\begin{array}{l}\text { 3D } \\
\text { simulation }\end{array}$ \\
\hline
\end{tabular}

The subject participating in the research is a 7-year-old boy, who was diagnosed as being with ASD on the mild side at the age of 3 years 10 months. Timmy (pseudonym for the subject) had never been in any treatment before the diagnosis and has been engaged in ABA training program for three years. The AI Wukong has been brought into the program on 16 January 2019 and it has been used as a reinfocer ever since. The subject was hooked by Wukong at first sight because of its interactive and innovative features. Wukong has become his best company and strongest reinforcer for two months and the interest seems ever-lasting. The two-month application of Wukong as a reinforcer is analyzed in accordance with SWOT matrix and the analytical report is summarized in the following diagram (see Diagram 1).

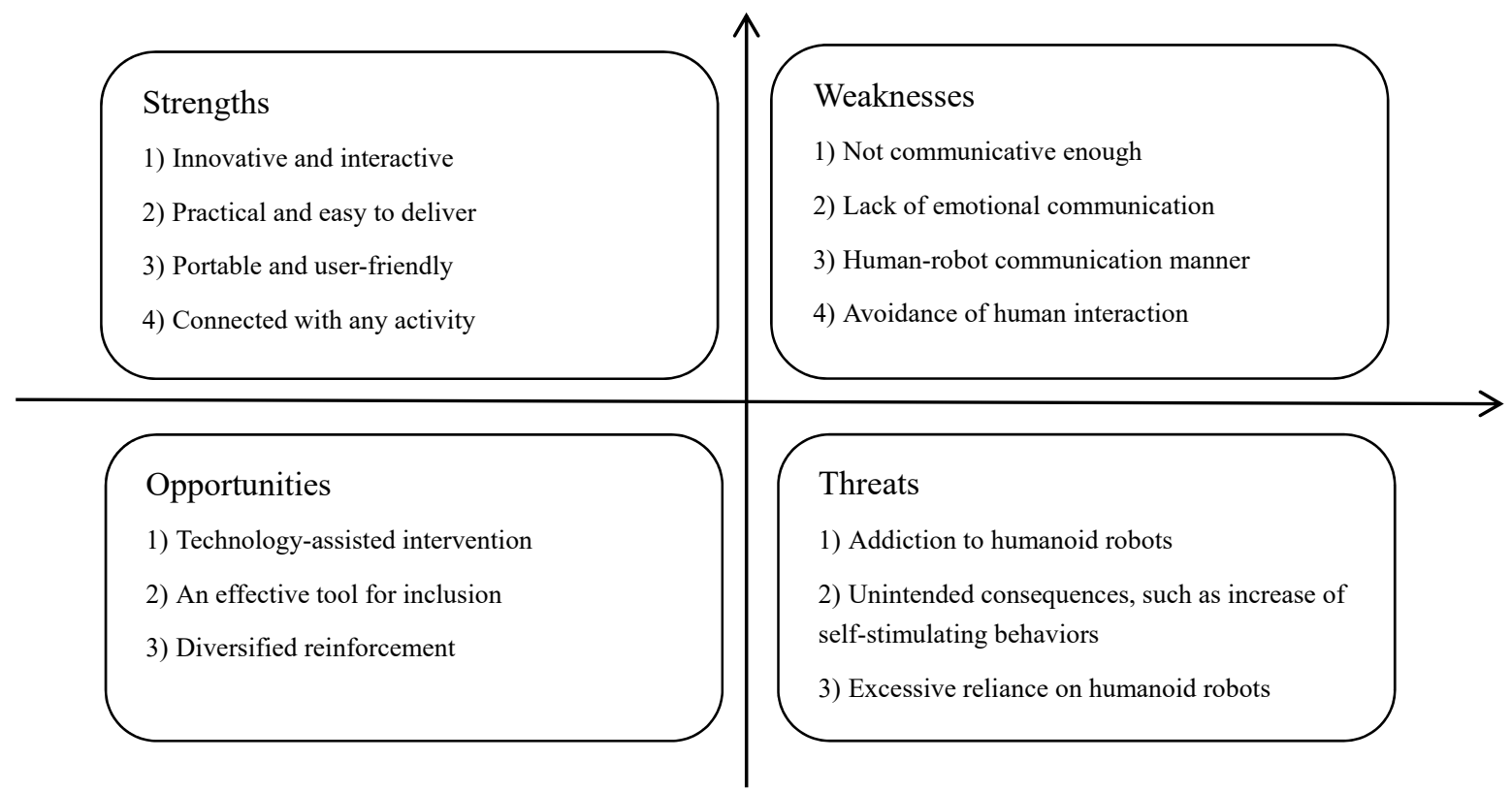

Diagram 1. SWOT Analysis of the Application of Wukong

With its interactive feature, Wukong attracts the child's attention at first sight. It is practical and easy to deliver; portable and user-friendly; and it is not solitary which can be connected with any activity. Wukong, as one of the strongest reinforcers, is delivered at the end of each intervention section and it functions. On the other hand, the weaknesses of Wukong as a reinforcer is quite obvious: 1) Wukong is not communicative enough. Users have to wake up the humanoid every time they are about the start a conversation which is different from the pattern of our daily conversation and it is impossible for children with ASD to increase the frequencies of starting a conversation focusing on one topic (See Scenario I). Wukong cannot display much non-verbal communication and the communication manner is different from that of human beings. The humanoid cannot detect and understand the child's emotional fluctuations which is displayed in Scenario II and III. Children with ASD usually have problems to control their emotions and playing tantrum is more often for them than typically-developed peers (See Picture 1). 
3) Child with ASD finds Wukong very attractive and every time when he is home, he buries himself with Wukong and repeats several functional sentences that he can master while neglecting his parents who try to have a conversation with him.

Table 2. Wukong's conversation with the ASD Child

\begin{tabular}{|c|c|c|}
\hline Scenario I & Scenario II & Scenario III \\
\hline Child: Wukong Wukong & Child: Wukong Wukong & Child: Wukong Wukong \\
\hline Wukong: Huh? & Wukong: Huh? & Wukong: Huh? \\
\hline Child: Could you sing me a song? & Child: Could you sing me the song "The & Child: Could you tell me a story? \\
\hline $\begin{array}{l}\text { Wukong: Sure! Listen attentively to this } \\
\text { song. (Wukong starts singing and the } \\
\text { child stops it at the beginning by } \\
\text { murmuring immediately.) }\end{array}$ & $\begin{array}{l}\text { Happy Day has Begun"? (The } \\
\text { pronunciation and intonation of the child } \\
\text { is not clear enough for Wukong to } \\
\text { understand) }\end{array}$ & $\begin{array}{l}\text { Wukong: (pause) The network is not } \\
\text { functioning and I am offline. } \\
\text { Child: (getting angry and starts to hit } \\
\text { Wukong) }\end{array}$ \\
\hline Child: Wukong Wukong & Wukong: (starts singing another song) & Wukong: The network is not functioning \\
\hline Wukong: Huh? & $\begin{array}{l}\text { Child: (getting angry and starts to hit } \\
\text { Wukong) }\end{array}$ & and I am offline. \\
\hline $\begin{array}{l}\text { Child: I want to listen to the Paw Patrol } \\
\text { story. }\end{array}$ & Wukong: It hurts! & $\begin{array}{l}\text { Child: (crying and yelling loudly) } \\
\text { Wukong. (no response) }\end{array}$ \\
\hline $\begin{array}{l}\text { Wukong: Here is the story. We will } \\
\text { continue with the previous section. } \\
\text { (Wukong starts telling a story and the } \\
\text { child stops it at the beginning by } \\
\text { murmuring immediately.) }\end{array}$ & $\begin{array}{l}\text { Child: (still hits Wukong) } \\
\text { Wukong: It hurts! } \\
\text { Child: (crying and yelling) } \\
\text { Wukong: (no response) }\end{array}$ & \\
\hline \multicolumn{3}{|l|}{ Child: Wukong Wukong } \\
\hline \multicolumn{3}{|l|}{ Wukong: Huh? } \\
\hline Child: Show me a dance. & & \\
\hline
\end{tabular}

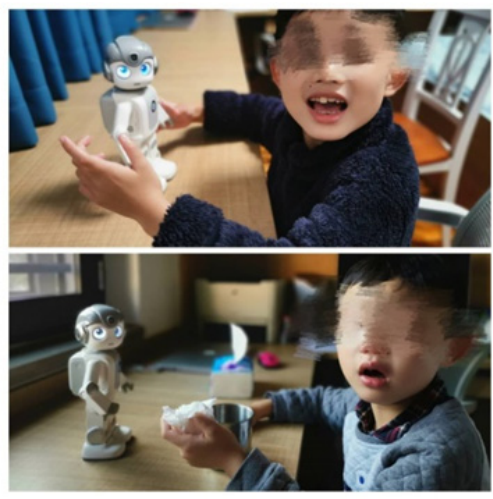

Picture 1: Child with ASD: Laughter and Tears

On the other hand, we also notice the opportunities of using humanoid in the intervention program as a useful reinforcer. At the end of every intervention trial, a reinforcer should be displayed promptly and Wukong can be integrated with any intervention activity which is based on ABA. More importantly, Wukong is also very popular with typically-developed children and it is the most effective tool for inclusion program. Inclusion has been proved to the most effective way for children with ASD to unleash their potential. In this research, researcher has brought Wukong to the kindergarten where the child with ASD stays. Wukong instantly attracted the attention of typically-developed children and they surrounded Wukong, starting to play with it (See Picture 2). Since the child with ASD is very familiar with the functions of Wukong, he introduced Wukong to his peers with great confidence and his peers immediately began to "admire" the ASD child's ability to control Wukong. This sharing experience is the first step for ASD child to get included into the mainstream education system. It has been proved that the humanoid is able to become the bond between the ASD child and the typically-developed ones, bridging the gap 
between them, serving as the foundation of communication.

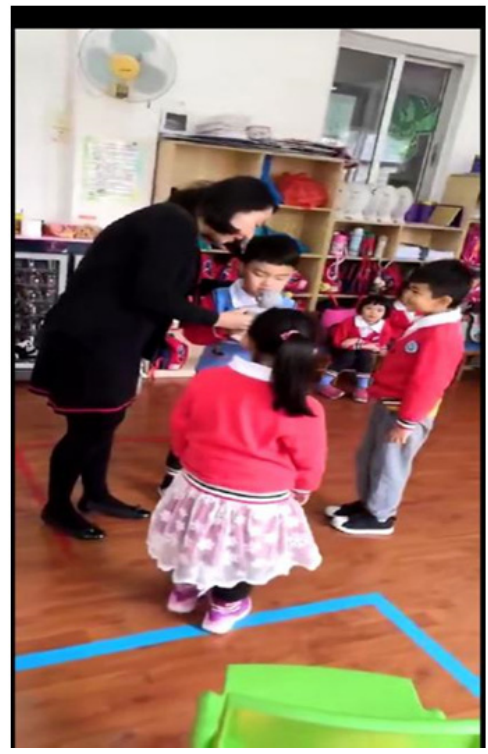

Picture 2. Wukong, Child with ASD and Typically-Developed Children

Admittedly, the two-month application also reveals the threats brought about by the humanoid: the reliance on the robot can result in more self-stimulating behaviors, such as self-talking and avoidance with human interaction. The child with ASD tend to be engaged with the humanoid robot probably because of its rigid way of communication which is one of the two features of ASD. The child is more accustomed to the inflexibility of the communication and avoids the contact with other people. It is a common phenomenon for ASD children to self-talk when he is feeling bored or under great pressure. The frequencies of this stimulating behavior increase with the application of Wukong.

The application of Wukong provides us with opportunities to find out advantages and disadvantages of humanoid robots in intervention, which is hoped to be solved in the future and the humanoid will play a more important role in intervention. Currently, humanoid robot is only suitable for being used as an effective reinforcer and its usage should be under control.

\section{Conclusion}

April 2, 2019 is the twelfth annual World Autism Awareness Day and the theme for this year is "Assistive Technologies, Active Participation". The focus is leveraging the use of assistive technologies for persons with autism as a tool in removing the barriers to their full social, economic and political participation in society, and in promoting equality, equity and inclusion. ASD is not a disease to be cured, rather, it is a disability which needs support and help. Currently, ABA is the most effective treatment for people with ASD, according to National Research Council and American Academy of Pediatrics. One of the essences of ABA is using reinforcement. The humanoid robot can be an effective reinforcer in trials and inclusion programs, but on the other hand, the weaknesses of it are quite obvious. We should maximize its advantages while minimizing its negative effects when it is being used as a reinforcer. The two-month application of Wukong, the most cutting-edged humanoid robot, with a single subject yields the preliminary results. How should we use the assistive technologies to unleash the potential of persons with ASD? What shall we do with assistive technologies for a better future for persons with ASD? These are remaining questions to be answered by researchers and scientists.

\section{References}

Alateeqi, N., \& Maria, F. J. (2019). Evidence-based treatments of autism spectrum disorder. Psychiatric Annals, 49(3), 115-119. https://doi.org/10.3928/00485713-20190204-01

American Psychiatric Association. (2013). Diagnostic and statistical manual of mental disorders (5th ed.). Washington, DC: American Psychiatric Association. https://doi.org/10.1176/appi.books. 9780890425596

Anderson, D. C., Henderson, H., \& Williams, D. P. (2017). Increasing pedal duration on a stationary recumbent 
bicycle in children with autism spectrum disorder by comparing the effectiveness of immediate versus delayed reinforcement. Palaestra, 31 Retrieved from https://search.proquest.com/docview/2039930214?accountid=11232

Beaver, B. N., Reeve, S. A., Reeve, K. F., \& DeBar, R. M. (2017). Self-reinforcement compared to teacher-delivered reinforcement during activity schedules on the iPod touch. Education and Training in Autism and Developmental Disabilities, 52(4), 393-404. Retrieved from https://search.proquest.com/docview/1967055450?accountid=11232

Bottema-Beutel, K., Park, H., \& So, Y. K. (2018). Commentary on social skills training curricula for individuals with ASD: Social interaction, authenticity, and stigma. Journal of Autism and Developmental Disorders, 48(3), 953-964. https://doi.org/10.1007/s10803-017-3400-1

Bradshaw, J., Koegel, L. K., \& Koegel, R. L. (2017). Improving functional language and social motivation with a parent-mediated intervention for toddlers with autism spectrum disorder. Journal of Autism and Developmental Disorders, 47(8), 2443-2458. https://doi.org/10.1007/s10803-017-3155-8

Brock, M. E., Dueker, S. A., \& Barczak, M. A. (2018). Brief report: Improving social outcomes for students with autism at recess through peer-mediated pivotal response training. Journal of Autism and Developmental Disorders, 48(6), 2224-2230. https://doi.org/10.1007/s10803-017-3435-3

Crooke, P. J., Garcia Winner, M., \& Olswang, L. B. (2016). Thinking socially: Teaching social knowledge to foster social behavioral change. Topics in Language Disorders, $36(3), 284$. https://doi.org/10.1097/TLD.0000000000000094

Duifhuis, E. A., Den Boer, J. C., Doornbos, A., Buitelaar, J. K., Oosterling, I. J., \& Klip, H. (2017). The effect of pivotal response treatment in children with autism spectrum disorders: A non-randomized study with a blinded outcome measure. Journal of Autism and Developmental Disorders, 47(2), 231-242. https://doi.org/10.1007/s10803-016-2916-0

Fritz, J. N., Jackson, L. M., Stiefler, N. A., Wimberly, B. S., \& Richardson, A. R. (2017). Noncontingent reinforcement without extinction plus differential reinforcement of alternative behavior during treatment of problem behavior. Journal of Applied Behavior Analysis, 50(3), 590-599. https://doi.org/10.1002/jaba.395

Fuller, E. A., \& Kaiser, A. P. (2019). The effects of early intervention on social communication outcomes for children with autism spectrum disorder: A meta-analysis. Journal of Autism and Developmental Disorders, 1-18. https://doi.org/10.1007/s10803-019-03927-z

Goldman, S. E., Sanderson, K. A., Lloyd, B. P., \& Barton, E. E. (2019). Effects of school-home communication with parent-implemented reinforcement on off-task behavior for students with ASD. Intellectual and Developmental Disabilities, 57(2), 95-111,172,174. https://doi.org/10.1352/1934-9556-57.2.95

Grenier, M., \& Yeaton, P. (2019). Social thinking skills and cooperative learning for students with autism. Journal of Physical Education, Recreation \& Dance, 90(3), 18-21. https://doi.org/10.1080/07303084.2019.1559675

Hobson, J. A., Tarver, L., Beurkens, N., \& Peter Hobson, R. (2016). The relation between severity of autism and caregiver-child interaction: A study in the context of relationship development intervention. Journal of Abnormal Child Psychology, 44(4), 745-755. https://doi.org/10.1007/s10802-015-0067-y

Huijnen, C. A. G. J., Lexis, M. A. S., Jansens, R., \& de Witte, L. P. (2016). Mapping robots to therapy and educational objectives for children with autism spectrum disorder. Journal of Autism and Developmental Disorders, 46(6), 2100-2114. https://doi.org/10.1007/s10803-016-2740-6

Huijnen, C. A. G. J., Lexis, M. A. S., Jansens, R. et al. (2019). Roles, Strengths and Challenges of Using Robots in Interventions for Children with Autism Spectrum Disorder (ASD). Journal of Autism Developmental Disorders, 49, 11. https://doi.org/10.1007/s10803-018-3683-x

Jessel, J., Ingvarsson, E. T., Whipple, R., \& Kirk, H. (2017). Increasing on-task behavior of an adolescent with autism using momentary differential reinforcement. Behavioral Interventions, 32(3), 248-254. https://doi.org/10.1002/bin.1480

Johnson, K. A., Vladescu, J. C., Kodak, T., \& Sidener, T. M. (2017). An assessment of differential reinforcement procedures for learners with autism spectrum disorder. Journal of Applied Behavior Analysis, 50(2), 290-303. https://doi.org/10.1002/jaba.372

Juliet, H. B. (2018). Three evidence-based strategies that support social skills and play among young children with autism spectrum disorders. Early Childhood Education Journal, 46(6), 665-672. 
https://doi.org/10.1007/s10643-018-0911-0

Loucas, T., Baird, G., Simonoff, E., \& Slonims, V. (2016). Phonological processing in children with specific language impairment with and without reading difficulties.International Journal of Language \& Communication Disorders, 51(5), 581-588. https://doi.org/10.1111/1460-6984.12225

MacNaul, H. L., \& Neely, L. C. (2018). Systematic review of differential reinforcement of alternative behavior without extinction for individuals with autism. Behavior Modification, 42(3), 398-421. https://doi.org/10.1177/0145445517740321

Matsuda, S., Omori, T., McCleery, J. P., \& Yamamoto, J. (2019). Comparing reinforcement values of facial expressions: An eye-tracking study. The Psychological Record, 1-8. https://doi.org/10.1007/s40732-019-00330-z

Mercer, J. (2017). Examining DIR/Floortime(TM) as a treatment for children with autism spectrum disorders. Research on Social Work Practice, 27(5), 625-635. https://doi.org/10.1177/1049731515583062

Montallana, K. L., Gard, B. M., Lotfizadeh, A. D., \& Poling, A. (2019). Inter-Rater Agreement for the Milestones and Barriers Assessments of the Verbal Behavior Milestones Assessment and Placement Program (VB-MAPP). Journal of autism and developmental disorders, 1-9. https://doi.org/10.1007/s10803-019-03879-4

Movahedazarhouligh, S. (2018). Teaching play skills to children with disabilities: Research-based interventions and practices. Early Childhood Education Journal, 46(6), 587-599. https://doi.org/10.1007/s10643-018-0917-7

Müller, E., Cannon, L. R., Kornblum, C., Clark, J., \& Powers, M. (2016). Description and preliminary evaluation of a curriculum for teaching conversational skills to children with high-functioning autism and other social cognition challenges. Language, Speech \& Hearing Services in Schools (Online), 47(3), 1-18. https://doi.org/10.1044/2016_LSHSS-15-0042

National Autism Center. (2015). National Standard Project. Randolph, MA: National Autism Center.

Park, I., \& Kim, Y. (2018). Effects of TEACCH structured teaching on independent work skills among individuals with severe disabilities. Education and Training in Autism and Developmental Disabilities, 53(4), 343-352. Retrieved from https://search.proquest.com/docview/2139455537?accountid=11232

Simut, R. E., Vanderfaeillie, J., Peca, A., Van, D. P., \& Vanderborght, B. (2016). Children with autism spectrum disorders make a fruit salad with probo, the social robot: An interaction study. Journal of Autism and Developmental Disorders, 46(1), 113-126. https://doi.org/10.1007/s10803-015-2556-9

Skinner, B. F. (1957). Verbal behavior. Englewood Cliffs: Prentice Hall. https://doi.org/10.1037/11256-000

Stolte, M., Hodgetts, S., \& Smith, V. (2016). A critical review of outcome measures used to evaluate the effectiveness of comprehensive, community based treatment for young children with ASD. Research in Autism Spectrum Disorders, 23, 221-234. https://doi.org/10.1016/j.rasd.2015.12.009

Sundberg, M. L. (2008). Verbal behavior milestones assessment and placement program: The VB-MAPP. Concord: AVB Press.

Sundberg, M. L. (2014). The verbal behavior milestones assessment and placement program: The VB-MAPP (2nd ed.). Concord: AVB Press.

Vandbakk, M., Olaff, H. S., \& Holth, P. (2019). Conditioned reinforcement: The effectiveness of Stimulus-Stimulus pairing and operant discrimination procedures. The Psychological Record, 69(1), 67-81. https://doi.org/10.1007/s40732-018-0318-8

Ventola, P. E., Yang, D., Abdullahi, S. M., Paisley, C. A., Braconnier, M. L., \& Sukhodolsky, D. G. (2016). Brief report: Reduced restricted and repetitive behaviors after pivotal response treatment. Journal of Autism and Developmental Disorders, 46(8), 2813-2820. https://doi.org/10.1007/s10803-016-2813-6

Vernon, T. W., Holden, A. N., Barrett, A. C., Bradshaw, J., Ko, J. A., McGarry, E. S., . . German, T. C. (2019). A pilot randomized clinical trial of an enhanced pivotal response treatment approach for young children with autism: The PRISM model. Journal of Autism and Developmental Disorders, 1-16. https://doi.org/10.1007/s10803-019-03909-1

Verschuur, R., Huskens, B., Verhoeven, L., \& Didden, R. (2017). Increasing opportunities for question-asking in school-aged children with autism spectrum disorder: Effectiveness of staff training in pivotal response 
treatment. Journal of Autism and Developmental Disorders, 47(2), 490-505. https://doi.org/10.1007/s10803-016-2966-3

Warren, Z. E., Zheng, Z., Swanson, A. R., Bekele, E., Zhang, L., Crittendon, J. A., \& Sarkar, N. (2015). Can robotic interaction improve joint attention skills? Journal of Autism and Developmental Disorders, 45(11), 3726-3734. https://doi.org/10.1007/s10803-013-1918-4

World Health Organization. (2018). International Classification of Diseases for Mortality and Morbidity Statistics (11th ed.). Geneva: World Health Organization.

\section{Copyrights}

Copyright for this article is retained by the author(s), with first publication rights granted to the journal.

This is an open-access article distributed under the terms and conditions of the Creative Commons Attribution license (http://creativecommons.org/licenses/by/4.0/). 